\title{
Selecting GLP-I agonists in the management of type 2 diabetes: differential pharmacology and therapeutic benefits of liraglutide and exenatide
}

This article was published in the following Dove Press journal:

Therapeutics and Clinical Risk Management

28 August 2010

Number of times this article has been viewed

\author{
Jonathan Pinkney' \\ Thomas Fox' \\ Lakshminarayan Ranganath ${ }^{2}$ \\ 'Department of Diabetes and \\ Endocrinology, Peninsula College of \\ Medicine and Dentistry, Plymouth, \\ United Kingdom; ${ }^{2}$ Department of \\ Clinical Biochemistry and Metabolic \\ Medicine, Royal Liverpool University \\ Hospital, Liverpool, United Kingdom
}

Correspondence: Jonathan Pinkney Department of Diabetes and Endocrinology, Peninsula College of Medicine and Dentistry, University Medicine, Level 7 Derriford Hospital, Plymouth Hospitals NHS Trust, Crownhill, Plymouth PL8 6DH,

United Kingdom

Tel +44- I 752793498

Email jonathan.pinkney@pms.ac.uk

\begin{abstract}
Failure of secretion of the incretin hormone glucagon-like peptide-1 (GLP-1) plays a prominent role in type 2 diabetes, and restoration of GLP-1 action is an important therapeutic objective. Although the short duration of action of GLP-1 renders it unsuited to therapeutic use, 2 long-acting GLP-1 receptor agonists, exenatide and liraglutide, represent a significant advance in treatment. In controlled trials, both produce short-term glucose-lowering effects, with the reduction in hemoglobin $\mathrm{A}_{1 \mathrm{c}}$ of up to $1.3 \%$. These responses are often superior to those observed with additional oral agents. However, unlike sulfonylureas, thiazolidinediones, or insulin, all of which lead to significant weight gain, GLP-1 receptor agonists uniquely result in long-term weight loss of around $5 \mathrm{~kg}$, and higher doses may enhance this further. Reduction in blood pressure of 2-7 $\mathrm{mm} \mathrm{Hg}$ also has been observed. Both drugs produce transient mild gastrointestinal side effects; although mild hypoglycemia can occur, this is usually in combination with other hypoglycemic therapies. However, serious hypoglycemia and acute pancreatitis are rare. The once-daily dosage of liraglutide makes it more convenient than twice-daily dosage of prandial exenatide, and a superior glucose-lowering effect was observed in the only head-tohead comparison reported so far. Besides cost, these considerations currently favor liraglutide over exenatide. Further studies are needed to confirm long-term safety, and most importantly, that short-term benefits translate into long-term reductions of diabetes-related cardiovascular events and other complications.
\end{abstract}

Keywords: diabetes, weight loss, glycemic control, blood pressure

\section{Overview of GLP-I}

The hormones secreted from the gut endocrine cells play key roles in the control of energy balance by regulating the assimilation, storage, and metabolism of nutrients. Disruption of these endocrine cells disturbs the normal control of body weight and insulin production and contributes to the development of type 2 diabetes (T2D). Two of these hormones, glucagon-like peptide-1 (GLP-1) and glucose-dependent insulinotropic polypeptide (GIP), are known as incretin hormones due to their ability to increase the $\beta$-cell insulin response to ingested glucose. ${ }^{1,2}$ It has been estimated that the incretin effect accounts for as much as $70 \%$ of insulin secretion in healthy persons and half of that in patients with T2D. ${ }^{3}$ Importantly, the incretin effect, in particular, postprandial production of GLP-1, is significantly impaired in patients with T2D. ${ }^{5}$

GLP-1 has been considered to be more important than GIP. GLP-1 is derived from the proglucagon gene expressed in pancreatic islet cells, L-cells of the small and large intestine, and neurons in the brainstem. Both transcription and translation are under the control of multiple tissue-specific regulatory mechanisms. ${ }^{6}$ The actions 
of GLP-1 are mediated through G-protein-coupled receptors widely expressed in pancreatic islet $\beta$ cells throughout the gastrointestinal tract, kidney, lung, heart, major blood vessels, adipose tissue, on gastric vagal afferents, and in many brain regions..$^{7-10}$ GLP-1 suppresses food intake through a pathway involving vagal afferent fibers, signaling to regions of the brainstem and hypothalamus. Thus, sustained administration of GLP-1 leads to weight loss in animals. Although the insulin response to GIP is impaired in T2D, the response to GLP-1 is preserved, ${ }^{11}$ making GLP-1 a feasible treatment. Furthermore, the administration of intravenous GLP-1 suppresses hyperglucagonemia in healthy subjects ${ }^{12}$ and normalizes blood glucose levels in patients with T2D. ${ }^{13}$ Gastric emptying is also delayed by GLP-1, and the increase in postprandial glucose is attenuated. ${ }^{14}$ Satiety is also increased, ${ }^{15}$ and the overall energy intake is reduced by treatment with GLP-1. ${ }^{16}$ Thus, GLP-1 has many useful effects that make it appealing as a potential treatment of T2D.

The principal problem with GLP-1 as a therapeutic agent is that the N-terminal is rapidly cleaved by the enzyme dipeptidyl peptidase-IV (DPP-IV) resulting in the generation of inactive GLP-1-(9-36) amide. ${ }^{17,18}$ As a result, the half-life of GLP-1 after secretion is around 1.5 minutes, ${ }^{19}$ which is insufficient for a convenient frequency of injections to restore serum GLP-1 levels in humans. Therefore, a series of longacting receptor agonists of GLP-1 have been developed, and this class of drug is now making a major impact in the treatment of T2D. This article compares the clinical pharmacology and therapeutics of the 2 currently available GLP-1 receptor agonists, exenatide and liraglutide, and comments on the choice between these drugs in clinical practice.

\section{Clinical pharmacology Exenatide}

Exenatide is a synthetic version of exendin-4, a molecule that is found in the saliva of the Gila monster. Exendin- 4 has been found to have GLP-mimetic actions as an insulinotropic agent. ${ }^{20}$ Exenatide is a larger peptide than GLP-1, at 39 rather than 20 amino acids, and shares 53\% homology. Owing to a substitution of glycine for alanine at position 8 , exenatide is resistant to degradation by DPP-IV. Exenatide binds more avidly to the GLP-1 receptor in humans than does GLP-1. ${ }^{21}$ These pharmacological differences make exenatide have a much longer half-life compared with GLP-1 (3.4-4 hours vs 1.5 minutes). Exenatide is detectable within the plasma 15 minutes after subcutaneous injection and remains detectable for up to 15 hours. As a peptide, exenatide is degraded rapidly in the stomach and, therefore, requires parenteral administration. Unlike GLP-1, exenatide undergoes renal excretion, and as a result, it has not been licensed for use in patients with estimated glomerular flow rate of $<30 \mathrm{~mL} / \mathrm{min}^{22,23}$ The administration of exenatide up to 1 hour before meals results in lower glucose levels postprandially than administration after a meal. ${ }^{24}$ These factors determine the recommended dosing regimen of exenatide, which is twice daily, up to 1 hour before meals, at least 6 hours apart.

\section{Liraglutide}

Liraglutide is $97 \%$ homologous with human GLP-1, but differs from native human GLP-1 by possessing an $\mathrm{Arg}^{34}$ to-Lys ${ }^{34}$ substitution and a C16 fatty acid moiety bridged by glutamate at Lys. ${ }^{26}$ These changes confer resistance to enzymatic cleavage while the fatty acid moiety binds noncovalently to albumin, thereby lowering the absorption from the injection site and also reducing renal clearance. Thus, liraglutide reaches peak plasma concentrations after 10-14 hours and has a half-life of 11-13 hours, making it suitable for once-daily administration irrespective of meal times. ${ }^{20}$ A property of GLP-1 receptor agonists that makes them attractive as therapeutic agents in diabetes is that insulin secretion ceases when euglycemia is achieved, thereby minimizing the risk of hypoglycemia. Renal impairment has been found to have little effect on the pharmacokinetics of liraglutide, suggesting that the drug is likely to be safe to use in patients with kidney disease. ${ }^{25}$

\section{Treatment of diabetes Exenatide}

Initial trials found that 1 month of treatment with exenatide by subcutaneous injection twice daily significantly reduced plasma glucose levels and consequently hemoglobin $\mathrm{A}_{1 \mathrm{c}}$ $\left(\mathrm{HbA}_{1 \mathrm{c}}\right)$ in patients with T2D. ${ }^{26}$ The beneficial effects of exenatide on glycemic control were confirmed by a 4-week, blinded, placebo-controlled trial, in which exenatide reduced $\mathrm{HbA}_{1 \mathrm{c}}$ by $0.8 \%-1.1 \%$ from baseline. Insulin secretion, as determined from the homeostasis model assessment, showed an increase of $50 \%-100 \%$ in those treated with exenatide at 14 and 28 days compared with baseline. ${ }^{27}$ Early trials did not demonstrate significant changes in weight and only encountered mild gastrointestinal side effects.

A series of good-quality, randomized, double-blinded, placebo-controlled phase III clinical trials have assessed the efficacy and tolerability of exenatide. ${ }^{28-30}$ The trials include combinations of exenatide or placebo with sulfonylurea, metformin, and metformin plus sulfonylurea. These studies 
are well designed but tend to suffer from relatively high drop-out rates. The primary end points were $\mathrm{HbA}_{1 \mathrm{c}}$ and safety, and the secondary end points were fasting plasma glucose level, weight, and adverse events.

A 30-week trial of exenatide at doses of 5 and $10 \mu \mathrm{g}$ daily vs placebo added to existing sulfonylurea therapy in patients with type 2 diabetes mellitus found a reduction in $\mathrm{HbA}_{1 \mathrm{c}}$ of $0.46 \%$ and $0.86 \%$, respectively, compared with a $0.12 \%$ increase in $\mathrm{HbA}_{1 \mathrm{c}}$ in the placebo group. ${ }^{28}$ Fasting plasma glucose was only significantly reduced in the $10 \mu \mathrm{g}$ exenatide group. Similar effects on $\mathrm{HbA}_{1 \mathrm{c}}$ were observed when exenatide was added to metformin monotherapy. ${ }^{29}$ After 30 weeks of treatment with metformin and exenatide at the 5 or $10 \mu \mathrm{g}$ doses, $\mathrm{HbA}_{1 \mathrm{c}}$ decreased by $0.4 \%$ and $0.78 \%$, respectively, compared with a small increase of $0.08 \%$ in $\mathrm{HbA}_{\mathrm{lc}}$ in the placebo group. Again, effects on fasting plasma glucose level were modest, reflecting the glucose-dependent insulinotropic effect of exenatide, reducing postprandial glucose more effectively than fasting glucose. In combination with metformin and sulfonylurea, exenatide $5 \mu \mathrm{g}$ reduced $\mathrm{HbA}_{1 \mathrm{c}}$ by $0.6 \%$ and $10 \mu \mathrm{g}$ reduced $\mathrm{HbA}_{1 \mathrm{c}}$ by $0.8 \%$ after 30 weeks. ${ }^{30}$

More recent studies of a design comparable to the aforementioned ones investigated the addition of exenatide or placebo to a combination of thiazolidinedione (pioglitazone or rosiglitazone) with or without metformin. ${ }^{31}$ In a 16-week study, $\mathrm{HbA}_{1 \mathrm{c}}$ was reduced by $0.98 \%$ compared with placebo. In a 24-week study, exenatide 5 and $10 \mu \mathrm{g}$ twice daily or placebo was given to drug-naive patients with T2D suboptimally controlled by diet and exercise. Both the 5 and $10 \mu \mathrm{g}$ doses of exenatide improved $\mathrm{HbA}_{1 \mathrm{c}}$ by $0.7 \%$ and $0.9 \%$, respectively, in addition to improvements in fasting and postprandial plasma glucose levels. A recent open-label study randomized patients to exenatide, rosiglitazone, or the combination of both and found the greatest reduction in $\mathrm{HbA}_{1 \mathrm{c}}$ of $-1.3 \%$ in the combination therapy group. The combination also produced improvements in both insulin sensitivity and firstand second-phase insulin secretion. ${ }^{32}$

The comparative efficacies of exenatide and insulin have been investigated in 2 open-label trials. In a 26-week study, patients with suboptimally controlled T2D on metformin and sulfonylurea were assigned to receive $10 \mu \mathrm{g}$ exenatide or oncedaily insulin glargine titrated to fasting blood glucose of $<5.6$ $\mathrm{mmol} / \mathrm{L} .{ }^{33}$ In both groups, $\mathrm{HbA}_{1 \mathrm{c}}$ was reduced by $1.1 \%$. In a 16-week duration crossover study of exenatide $10 \mu \mathrm{g}$ administered twice-daily vs once-daily insulin glargine, equivalent reductions of $1.36 \%$ were observed in $\mathrm{HbA}_{1 \mathrm{c}} \cdot{ }^{34}$ Similar effects were found when exenatide $10 \mu \mathrm{g}$ twice daily was compared with biphasic insulin aspart, in which $\mathrm{HbA}_{1 \mathrm{c}}$ levels were reduced by $1.04 \%$ vs $0.89 \%$, respectively. ${ }^{35}$ In these comparisons of insulin and exenatide, exenatide reduced postprandial glucose more effectively, whereas insulin produced greater reductions in fasting plasma glucose. Bunck et al ${ }^{36}$ randomized 69 patients with T2D, already treated with metformin, to 12-months treatment with exenatide or once-daily insulin glargine. The dose of exenatide varied from $5 \mu \mathrm{g}$ twice daily to $15 \mu \mathrm{g}$ thrice daily. The reductions in $\mathrm{HbA}_{\mathrm{lc}}$ were in line with those in other studies ( $0.8 \%$ and $0.7 \%$, respectively), as were reductions in fasting plasma glucose (1.6 and $2.9 \mathrm{mmol} / \mathrm{L}$, respectively). At the end of the study period, both exenatide and insulin glargine were discontinued. Four weeks later, $\mathrm{HbA}_{1 \mathrm{c}}$ and fasting plasma glucose had returned to pretreatment levels, indicating that continuous treatment with exenatide is required to maintain its efficacy. Data from an open-label extension to 3 double-blinded, placebo-controlled trials including 217 patients, with a mean body mass index (BMI) of $34 \mathrm{~kg} / \mathrm{m}^{2}$, receiving treatment with exenatide over a period of 3 years have also been reported. A mean reduction of $1.0 \%$ in $\mathrm{HbA}_{1 \mathrm{c}}$ was preserved for up to 3 years. ${ }^{37}$ Finally, in a study of 235 overweight patients inadequately controlled on 2 or 3 oral hypoglycemic agents and randomized to add-on exenatide or insulin glargine, similar mean $\mathrm{HbA}_{1 \mathrm{c}}$ reductions of -1.25 and $-1.26 \%$, respectively, were observed. However, $53.4 \%$ of exenatide-treated patients reached the composite end point of $\mathrm{HbA}_{1 \mathrm{c}}<7 \%$ and weight gain $<1 \mathrm{~kg}$, compared with just $19.8 \%$ of the insulin glargine-treated group. ${ }^{38}$

The rates of hypoglycemia observed with exenatide treatment are largely dependent on the drugs with which it is combined. When exenatide was used alone, there were low rates of mild hypoglycemia ( $4 \%-5 \%$ and not significantly different from placebo), and no severe hypoglycemic events were reported. ${ }^{39}$ When exenatide was used in combination with metformin or in combination with both metformin and thiazolidinedione, there were also no increased risks of hypoglycemia. ${ }^{29,31}$ However, when it was combined with sulfonylurea (either alone or with metformin), there was an increase in the risk of mild to moderate hypoglycemia compared with placebo. ${ }^{28,30}$ There was only one incident of severe hypoglycemia in a patient treated with exenatide $5 \mu \mathrm{g}$ and sulfonylurea that required assistance from a third person. The incidence of hypoglycemia was similar when once-daily insulin glargine was compared with twice-daily exenatide $10 \mu \mathrm{g} .{ }^{33}$ Most incidences of hypoglycemia were mild or moderate, but there were 4 episodes of major hypoglycemia in each group. Hypoglycemia was more common in those patients achieving a lower target level of $\mathrm{HbA}_{1 \mathrm{c}}<7 \%(61 \%$ 
with exenatide and $68 \%$ with insulin glargine). Nocturnal hypoglycemia was also more common in the insulin glarginetreated group, while daytime hypoglycemia was more common in the exenatide-treated group. Similar findings were reported in the study of Davies et al. ${ }^{38}$ Although the occurrence of hypoglycemia may reflect an overall reduction in glucose levels that predisposes patients to a greater risk of hypoglycemia from concomitant administration of sulfonylureas, in vitro studies have shown that GLP-1 augments the insulin-releasing action of sulfonylureas. ${ }^{40}$ Therefore, the combination of a GLP-1 receptor agonist and sulfonylurea may be intrinsically more likely to result in hypoglycemia because of the closely related mechanism of action of these 2 classes of drugs.

Antibodies to exenatide were detected in approximately $40 \%-50 \%$ of patients receiving exenatide in phase III trials. ${ }^{28-30}$ The presence of antibodies appears to have no correlation with drug action, glycemic control, or adverse effects. Although the most common adverse effects are gastrointestinal (nausea, vomiting, and abdominal discomfort), exenatide is generally well tolerated. The gastrointestinal side effects were generally mild to moderate and tended to decrease with duration of treatment. Slow titration of exenatide also has been shown to reduce the rate of gastrointestinal side effects. ${ }^{41}$ The percentage of withdrawals attributed to nausea was low. The principal clinical trials of exenatide in patients with T2D are summarized in Table 1.

Exenatide has also been studied in combination with insulin, although this use currently remains off license. In an observational study of 134 patients treated with exenatide and insulin for at least 12 months, the addition of exenatide was associated with $45 \%$ discontinuation of soluble insulin, an average 9 units of reduction in soluble insulin doses, reduction in numbers of insulin injections from 2 to 1 , and $59 \%$ discontinuation of sulfonylurea treatment. Despite these treatment reductions, there was a mean reduction of $0.87 \%$ in $\mathrm{HbA}_{1 \mathrm{c}}{ }^{42}$ In another retrospective observational study of 268 patients treated with both exenatide and insulin for up to 27 months, mean reductions in $\mathrm{HbA}_{1 \mathrm{c}}$ were around $-55 \%$, with reductions in soluble insulin doses of up to $55 \% .{ }^{43}$

\section{Liraglutide}

Early randomized controlled studies using liraglutide at low doses in patients with T2D found that this drug was well tolerated, at least as effective as metformin, and was not associated with weight gain. ${ }^{44,45}$ The efficacy of the drug was confirmed in a randomized, placebo-controlled, dose-ranging study of
5 weeks duration. Liraglutide alone reduced $\mathrm{HbA}_{1 \mathrm{c}}$ by $0.8 \%$, fasting plasma glucose by $3.9 \mathrm{mmol} / \mathrm{L}$, and body weight by $2.2 \mathrm{~kg}$ compared with the combination of liraglutide and metformin. In addition, the combination therapy of liraglutide and metformin vs metformin and glimepiride significantly reduced the fasting glucose by $1.2 \mathrm{mmol} / \mathrm{L} .{ }^{46} \mathrm{In}$ another study of 14 weeks duration, liraglutide exhibited a dose-dependent decrease of $\mathrm{HbA}_{1 \mathrm{c}}$ and increased the proportion of patients achieving good glycemic control. ${ }^{47}$

The role of liraglutide in the treatment of diabetes has been further defined in a programme of large scale, longerduration clinical studies initiated by the manufacturers. This programme, known as the "Liraglutide Effect and Action in Diabetes" (LEAD) programme, has compared liraglutide with existing oral hypoglycemic therapies, as a single agent and in combinations. These trials are summarized in Table 2. LEAD 3 compared liraglutide with sulfonylurea glimepiride. In LEAD 1, 2, and 4 studies, liraglutide was added to other oral hypoglycemic agents. In LEAD 5, liraglutide and insulin glargine were compared as add-on therapy with metformin and glimepiride. Finally, LEAD 6 compared the addition of liraglutide or exenatide to treatment with metformin and/or glimepiride. These trials were all well-designed, controlled studies with a priori power calculations. Generally, follow-up and ascertainment of outcomes were well conducted, and apart from the LEAD 3 study, ${ }^{48}$ drop-out rates were low.

In the LEAD study programme, reductions in $\mathrm{HbA}_{1 \mathrm{c}}$ with addition of liraglutide ranged between $0.8 \%-1.5 \%$ at 1.2 and $1.8 \mathrm{mg}$ doses, and liraglutide appeared somewhat more effective in patients who had previously received monotherapy rather than combination therapy. ${ }^{49,50}$ The proportion of patients achieving glycemic targets with liraglutide was also consistently higher than that in the comparison groups. Notably, the LEAD 6 is the only study so far to compare liraglutide and exenatide. This 26-week trial randomized 233 patients to liraglutide $1.8 \mathrm{mg}$ daily and 231 to exenatide $10 \mu \mathrm{g}$ twice daily. The mean BMI of these patients was approximately $33 \mathrm{~kg} / \mathrm{m}^{2}$ and mean $\mathrm{HbA}_{1 \mathrm{c}}$ at baseline was $8.2 \%$. The patients were already treated with metformin, sulfonylurea, or both. Liraglutide lowered mean $\mathrm{HbA}_{1 \mathrm{c}}$ by $1.12 \%$ compared with $0.79 \%$ with exenatide, which gave a significant treatment difference. About $54 \%$ of liraglutidetreated patients achieved $\mathrm{HbA}_{1 \mathrm{c}}<7 \%$ compared with $43 \%$ of exenatide-treated group. Fasting blood glucose level was lower with liraglutide, but postprandial blood glucose level was higher. ${ }^{51}$ Overall, this study suggested a small but significant benefit of liraglutide over exenatide. 


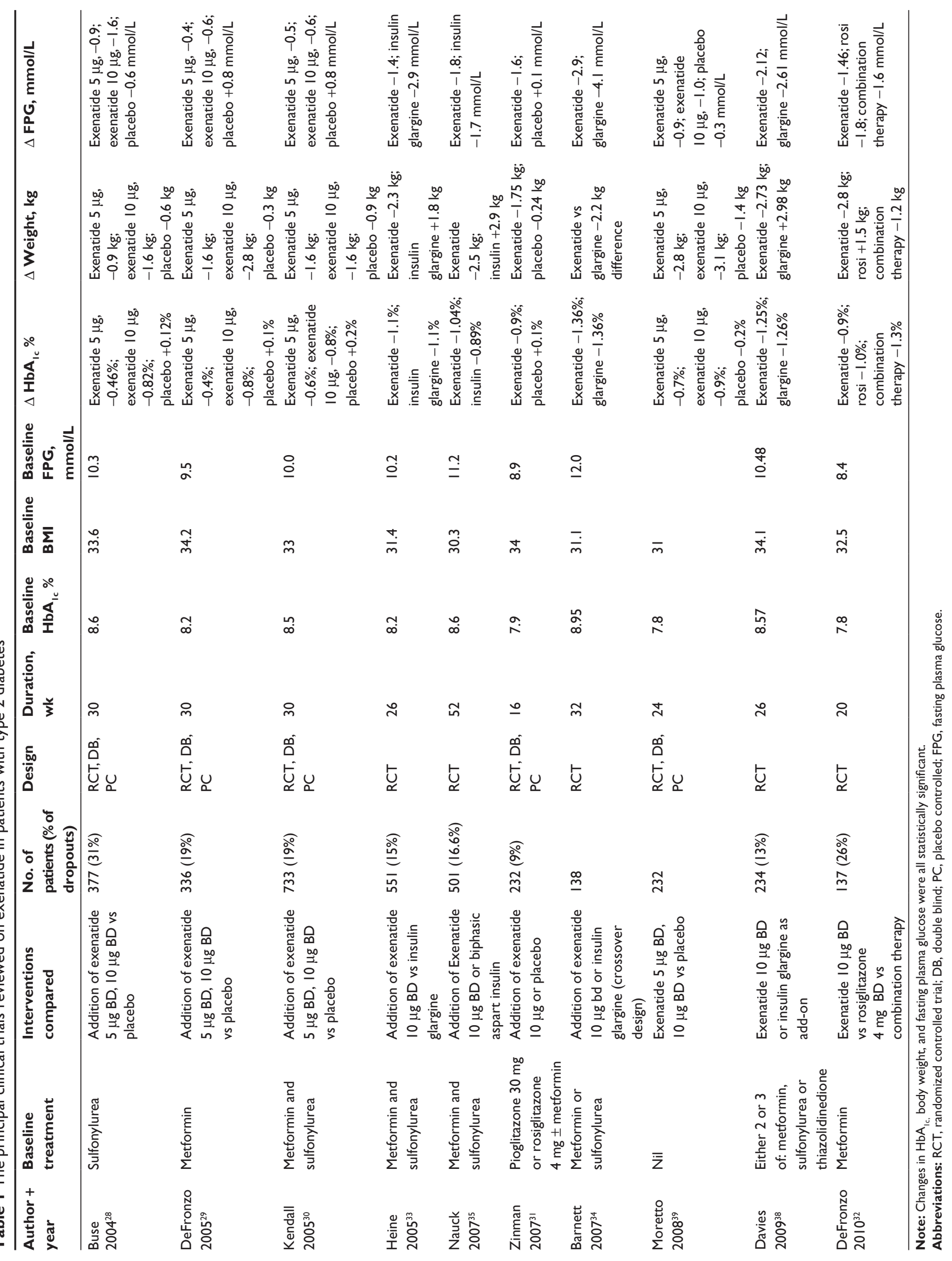




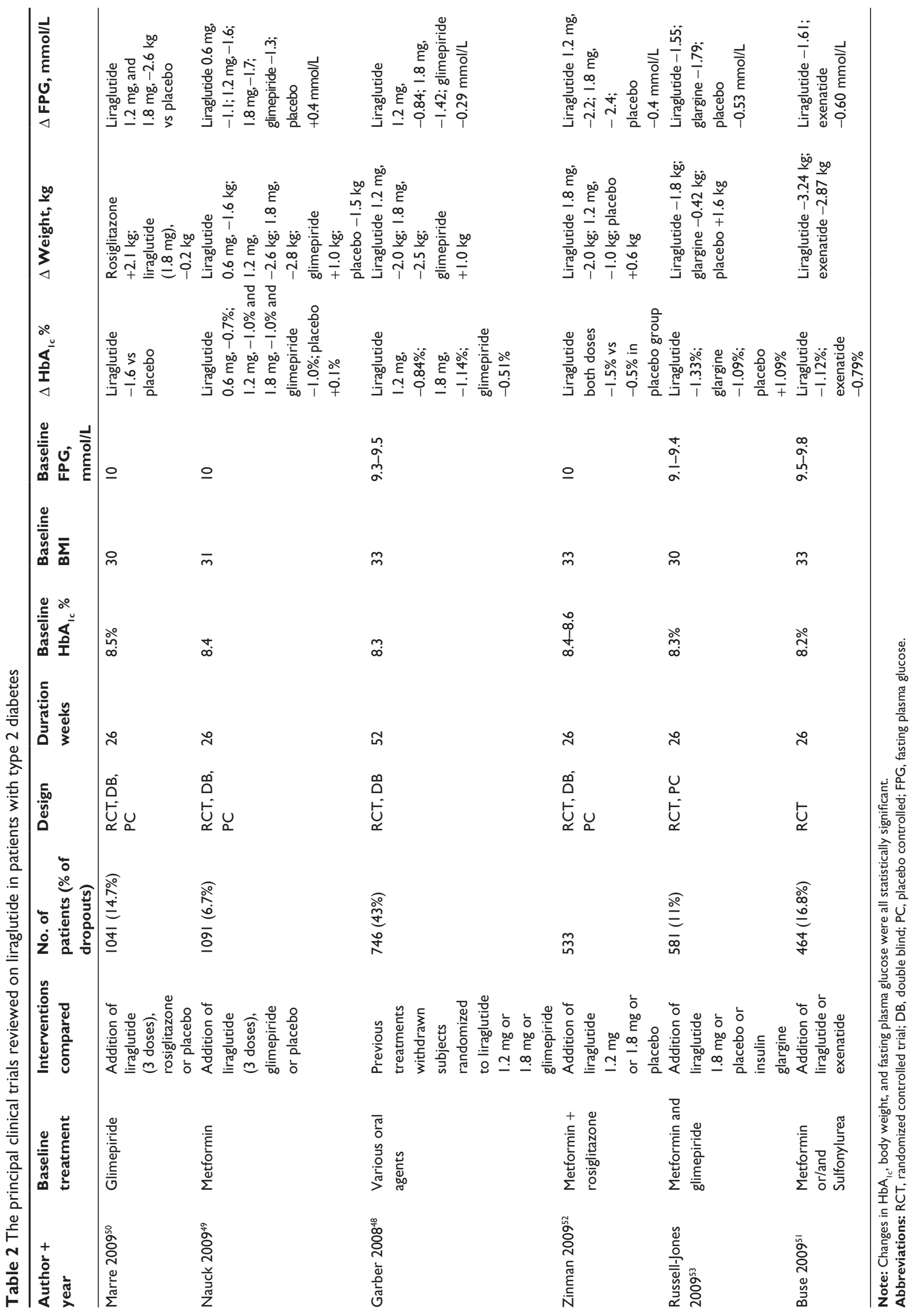


In LEAD 3 and LEAD 2, the rates of minor hypoglycemia were significantly lower in liraglutide-treated group than in glimepiride-treated groups, and no major hypoglycemic events were recorded in these studies. ${ }^{48,49}$ In LEAD 1, in which the baseline treatment was with sulfonylurea, minor hypoglycemia was more frequent with liraglutide add-on treatment compared with rosiglitazone add-on treatment. ${ }^{50}$ In LEAD 4, the rate of minor hypoglycemia was also higher with liraglutide than with placebo, although no serious hypoglycemia was observed. ${ }^{52}$ In LEAD 5, the frequency of minor hypoglycemia was similar with both insulin glargine and liraglutide, although 5 patients treated with liraglutide reported major hypoglycemic events..$^{53}$ Finally, in LEAD 6 , liraglutide was associated with fewer minor hypoglycemic events than exenatide, and 2 patients receiving treatment with exenatide and sulfonylurea experienced major hypoglycemia. ${ }^{51}$ In patients receiving liraglutide in addition to metformin or rosiglitazone, the risk of hypoglycemia was very low. Thus, the risk of hypoglycemia with GLP receptor antagonists appears higher in specific combination therapy with sulfonylureas.

The most frequent adverse effects are gastrointestinal intolerance, especially nausea. However, this subsides soon in most patients. In LEAD 6, liraglutide and exenatide produced similar initial rates of nausea, although by the end of the study, there was a significantly greater rate of nausea in the exenatide-treated group. Although adverse event rates were low, the liraglutide group reported slightly more serious and severe adverse events than the exenatide group. ${ }^{51}$ Six cases of pancreatitis were also reported during the LEAD programme, and all but 5 were in liraglutide-treated patients. In LEAD 6, although there was 1 episode of mild pancreatitis in the liraglutide-treated group, liraglutide treatment was continued in that patient. ${ }^{51}$ However, a recent commentary on this subject draws attention to 7 reported cases of pancreatitis out of 4,257 patients treated in phase II and III trials of liraglutide compared with just 1 case of pancreatitis in the 2,381 patients who received comparator treatments. After adjustment for patient-years of exposure to liraglutide, this study represented a 4-to-1 imbalance between the liraglutide and comparator groups. ${ }^{54}$ Therefore, although there may be a small risk of pancreatitis, the number of patients affected is small, and so the magnitude of this risk is difficult to determine.

The long-term treatment of rodents with liraglutide was found to cause thyroid C-cell hyperplasia, which raised the concerns that long-acting GLP-1 agonists might carry an increased risk of medullary thyroid cancer. Although the primate C-cells are apparently much less sensitive to GLP-1 receptor agonists ${ }^{55}$ and this highlights the need for long-term postmarketing surveillance of new classes of drugs.

\section{Effects on body weight \\ Exenatide}

Exenatide has consistently caused significant weight loss in a range of clinical trials. These effects are summarized in Table 1. As a GLP-1 receptor agonist, exenatide also has a variety of nonglycemic effects on appetite and gastric emptying. Three placebo-controlled trials have demonstrated significant dose-dependent weight loss with exenatide compared with placebo. When exenatide was added to sulfonylurea therapy alone, there was a weight loss of $1.6 \mathrm{~kg}$ in the $10-\mu \mathrm{g}$ dose group compared with $0.6 \mathrm{~kg}$ weight loss in the placebo group. ${ }^{28}$ When exenatide at doses of 10 and $5 \mu \mathrm{g}$ was added to metformin and sulfonylurea, it elicited the weight loss of $1.6 \mathrm{~kg}$ in both groups compared with $0.9 \mathrm{~kg}$ in the placebo group..$^{30}$ Exenatide added to metformin alone caused the greatest weight reduction of 1.6 and $2.8 \mathrm{~kg}$ at the 5 and $10 \mu \mathrm{g}$ doses, respectively. ${ }^{29}$ Similar weight reduction was observed with exenatide at $10-\mu \mathrm{g}$ dose in patients treated with a combination of rosiglitazone or pioglitazone with or without metformin, with an average weight loss of $1.74 \mathrm{~kg}$ over 32 weeks. ${ }^{31}$ In another randomized study, exenatide $10 \mu \mathrm{g}$ twice daily combined with rosiglitazone $4 \mathrm{mg}$ elicited average weight loss of $1.2 \mathrm{~kg}$ in contrast to the weight gain of $1.5 \mathrm{~kg}$ with rosiglitazone alone and weight loss of $2.8 \mathrm{~kg}$ with exenatide alone. ${ }^{32}$

In the open-label extension of the 3 phase III clinical trials of exenatide, there was a progressive weight loss in those treated with exenatide $10 \mu \mathrm{g}$ for 3 years. Although this was an uncontrolled trial, in 217 subjects, the mean weight loss was $5.3 \mathrm{~kg}$ at 3 years. ${ }^{37}$ In a 30 -week study, mean weight loss was $3.0 \mathrm{~kg}$, whereas this also reached $5.3 \mathrm{~kg}$ after 82 weeks. ${ }^{56}$ Therefore, weight loss with exenatide may reach a plateau after about 18 months. In these studies, weight loss with exenatide was apparently independent of gastrointestinal side effects.

Exenatide as monotherapy in drug-naive patients with T2D has also shown significant weight loss. After 24 weeks of treatment with exenatide $5 \mu \mathrm{g}, 10 \mu \mathrm{g}$, or placebo, mean weight loss was $2.8,3.1$, or $1.4 \mathrm{~kg}$, respectively. ${ }^{39}$ In openlabel comparisons of exenatide, insulin glargine, and biphasic insulin aspart, the value of exenatide as an adjunctive therapy was highlighted. ${ }^{33,35,38}$ Although these 3 therapies improved glycemic control to comparable extents, exenatide was associated with significant weight loss, whereas insulin leads to weight gain. When insulin glargine was added to metformin 
and sulfonylurea, the weight gain was $1.8 \mathrm{~kg}$ compared with weight loss of $2.3 \mathrm{~kg}$ in the exenatide-treated patients. ${ }^{33}$ After 1 year of treatment with biphasic insulin aspart, the weight gain was $2.9 \mathrm{~kg}$ compared with weight loss of $2.5 \mathrm{~kg}$ with exenatide. ${ }^{35}$ In another study, add-on treatment with exenatide resulted in $2.73 \mathrm{~kg}$ of weight loss compared with $2.98 \mathrm{~kg}$ weight gain in the glargine-treated group, an overall difference of $5.71 \mathrm{~kg} .{ }^{38}$ Interestingly, exenatide also evoked average weight losses of $5.2 \mathrm{~kg}^{42}$ and $5.5 \mathrm{~kg}^{43}$ when used in combination with insulin. Finally, in a small open-label trial in women with polycystic ovary syndrome, the effect of treatment with metformin alone, exenatide alone, or the combination of both on the menstrual regularity and weight was evaluated. Metformin alone led to the weight loss of $1.6 \mathrm{~kg}$, exenatide alone to $3.2 \mathrm{~kg}$, and the combination of both to $6 \mathrm{~kg} .{ }^{57}$ Otherwise, there are only limited published data on the use of exenatide in patients with nondiabetic obesity.

\section{Liraglutide}

The beneficial effect of liraglutide on body weight was observed in all the early studies of this drug, ${ }^{44-47}$ and significant dose-dependent weight loss was demonstrated in all of the LEAD studies. In the monotherapy study (LEAD 3), absolute weight loss was $2.5 \mathrm{~kg}$ at the $1.8 \mathrm{mg}$ dose and $2.1 \mathrm{~kg}$ at the $1.2 \mathrm{mg}$ dose. Weight loss was greatest in combination with metformin: $2.8 \mathrm{~kg}$ with the $1.8 \mathrm{mg}$ dose and $2.6 \mathrm{~kg}$ with the $1.2 \mathrm{mg}$ dose. ${ }^{49}$ In LEAD 1, the addition of liraglutide to sulfonylurea abolished the weight gain observed in the group treated with the combination of sulfonylurea and rosiglitazone. ${ }^{50}$ In combination with metformin and rosiglitazone, weight loss was $2 \mathrm{~kg}$ at the $1.8 \mathrm{mg}$ dose and $1 \mathrm{~kg}$ at the $1.2 \mathrm{mg}$ dose. ${ }^{52}$ In LEAD 5, treatment with insulin glargine increased weight by $1.6 \mathrm{~kg}$, whereas liraglutide decreased weight by $1.8 \mathrm{~kg} .{ }^{53}$ In LEAD 6, at the $1.8 \mathrm{mg}$ dose, liraglutide elicited weight loss of $3.2 \mathrm{~kg}$ compared with $2.9 \mathrm{~kg}$ in the exenatide group. ${ }^{51}$ The reduction of body weight with liraglutide is confirmed to result from a reduction in body fat. ${ }^{58}$ Therefore, liraglutide-induced weight loss is maximal in metformintreated patients, but liraglutide appears to offset the weight gain that often results from treatment with sulfonylurea, thiazolidinediones, or insulin. These effects on body weight are summarized in Table 2.

A potential role of liraglutide as a weight loss treatment is emerging. In a recently reported trial of 20 weeks duration, 564 obese individuals with BMI $30-40 \mathrm{~kg} / \mathrm{m}^{2}$ were randomly assigned to any one of 4 doses of liraglutide (1.2, 1.8, 2.4, or $3.0 \mathrm{mg}$ ), placebo, or orlistat. All subjects were advised for a 500-calorie energy-deficit diet and to increase physical activity. Subjects on liraglutide lost significantly more weight than did those on placebo and orlistat. Mean weight loss with these 4 doses of liraglutide was $4.8,5.5,6.3$, and $7.2 \mathrm{~kg}$ vs $2.8 \mathrm{~kg}$ in the placebo group and $4.1 \mathrm{~kg}$ in the orlistat group. About $76 \%$ of individuals lost more than $5 \%$ weight with liraglutide $3.0 \mathrm{mg}$ compared with $30 \%$ in the placebo or $44 \%$ in the orlistat groups. Liraglutide reduced blood pressure at all doses and improved glucose tolerance. Although transient nausea was the commonest adverse effect, liraglutide was generally well tolerated at these higher doses. ${ }^{59}$ Therefore, liraglutide is a promising drug for weight loss. All these observations are more important in view of the withdrawal of rimonabant and sibutramine, which has severely restricted the current choice of drugs for weight loss.

\section{Effects on blood pressure}

An unexpected but consistent effect of liraglutide in the LEAD programme was the modest reduction of blood pressure, ranging from 2.1 to $6.7 \mathrm{~mm} \mathrm{Hg.}{ }^{49,51-53,60}$ GLP-1 has been reported to have a natriuretic effect, ${ }^{61}$ which might explain its effect on blood pressure. In contrast, a recently reported randomized, controlled trial in patients treated with metformin and/or thiazolidinedione compared the effect of exenatide or placebo on ambulatory blood pressure. However, although a nonsignificant trend was suggested, ${ }^{62}$ no reduction of blood pressure was observed with exenatide. However, in a pooled analysis of data from 6 trials involving 2,171 patients, systolic blood pressure was reduced in the exenatide-treated groups by $2.8 \mathrm{~mm} \mathrm{Hg}$ when compared with placebo and by $3.7 \mathrm{~mm} \mathrm{Hg}$ when compared with insulin-treated patients, but no effect was observed on diastolic blood pressure. The reduction in blood pressure appeared highest in patients with systolic blood pressure of $>150 \mathrm{~mm} \mathrm{Hg}$. A weak correlation between weight loss and blood pressure reduction was also observed. ${ }^{63}$ Vasorelaxant effects of GLP-1 have been observed in various animal and in vitro studies, ${ }^{64-66}$ and infusion of GLP-1 in humans with T2D leads to increased flow-mediated vasodilatation in the brachial artery. ${ }^{67}$ Therefore, GLP-1 and GLP-1 receptor agonists appear to possess the useful additional property of reducing blood pressure. Furthermore, one may speculate that reduced GLP-1 secretion could be a factor contributing to the increased prevalence of hypertension among patients with T2D.

\section{Conclusions}

GLP-1 receptor agonists are one of the most significant recent advances in the treatment of T2D. Although weight loss is 
regularly identified as a treatment priority for patients with $\mathrm{T} 2 \mathrm{D}$, it is ironic that many patients find that the established pharmacological approaches to treatment with sulfonylureas, thiazolidinediones, and insulin only improve glycemic control at the cost of significant weight gain. GLP-1 receptor agonists have rapidly established a place as add-on therapy to other oral agents, in preference to a direct move onto insulin treatment. Clearly, long-term studies will be required to compare these strategies. GLP-1 receptor agonists also seem to have a significant potential as weight loss drugs in persons both with and without T2D; however, in view of the historical problems with weight loss drugs, it is important to demonstrate their long-term safety and efficacy in this role. Because prevention of cardiovascular disease is an important objective in treating patients with $\mathrm{T} 2 \mathrm{D}$, it is now essential to demonstrate the apparently favorable short-term effects of GLP-1 receptor agonists on glycemic control and weight observed in clinical trials to date translate into safe and effective long-term reductions of diabetes-related cardiovascular events and other relevant clinical end points.

Liraglutide and exenatide differ in several respects, and these differences are likely to influence clinical choices. The once-daily dosage of liraglutide makes this drug more appealing than exenatide for a group of patients who are often already receiving many different medicines. The convenience of being able to take liraglutide at any time of the day, irrespective of meal times, is also attractive. The LEAD 6 study suggests that liraglutide is somewhat more effective than exenatide in lowering the blood glucose and $\mathrm{HbA}_{1 \mathrm{c}}$ levels. Both drugs are relatively well tolerated, and serious hypoglycemia is very unusual; nevertheless, liraglutide may be less liable to cause hypoglycemia. Liraglutide also consistently reduces blood pressures, whereas this effect may be less marked or absent with exenatide. Compared with exenatide, the absence of allergy to liraglutide, which is largely homologous with human GLP-1, also favors liraglutide. Pharmacokinetic considerations suggest that there may be less risk of drug accumulation with liraglutide compared with exenatide, so that liraglutide might be tolerated better by patients with diabetic nephropathy. However, we were unable to identify any additional reports on patients with advanced nephropathy. Although both liraglutide and exenatide induce gastrointestinal side effects, this effect is of significantly shorter duration with liraglutide, enabling more patients to continue the drug. Finally, while both drugs clearly elicit weight loss, which is highly desirable for all patients with T2D, the observation that liraglutide is significantly more effective than orlistat in a randomized, controlled trial may also make this drug an important treatment choice for many patients. Thus, GLP-1 receptor agonists are becoming favorable alternative to the existing hypoglycemic therapies that are of modest efficacy and usually result in weight gain.

Currently, several considerations appear to favor the selection of liraglutide over exenatide. However, the development of new long-acting formulations such as once-weekly exenatide, which was more effective in lowering $\mathrm{HbA}_{1 \mathrm{c}}$ than exenatide administered twice daily ${ }^{68}$ clearly has the potential to influence this choice. Several new GLP-1 receptor agonists, including agents that may be taken orally, are also in development, and it remains to be seen how such drugs will compare with the existing 2 agents.

\section{Disclosure}

The authors report no conflicts of interest in this work.

\section{References}

1. Elrick H, Stimmler L, Hlad CJ Jr, Arai Y. Plasma insulin response to oral and intravenous glucose administration. J Clin Endocrinol Metab. 1964;24:1076-1082.

2. McIntyre N, Holdsworth CD, Turner DS. Intestinal factors in the control of insulin secretion. J Clin Endocrinol Metab. 1965;25(10): 1317-1324.

3. Nauck MA, Homberger E, Siegel EG, et al. Incretin effects of increasing glucose loads in man calculated from venous insulin and C-peptide responses. J Clin Endocrinol Metab. 1986;63(2):492-498.

4. Nauck M, Stockmann F, Ebert R, Creutzfeldt W. Reduced incretin effect in type 2 (non-insulin-dependent) diabetes. Diabetologia. 1986; 29(1):46-52.

5. Vilsboll T, Krarup T, Deacon CF, Madsbad S, Holst JJ. Reduced postprandial concentrations of intact biologically active glucagonlike peptide 1 in type 2 diabetic patients. Diabetes. 2001;50(3): 609-613.

6. Nian M, Gu J, Irwin DM, Drucker DJ. Human glucagon gene promoter sequences regulating tissue-specific versus nutrient-regulated gene expression. Am J Physiol Regul Integr Comp Physiol. 2002;282(1): R173-R183.

7. Egan JM, Montrose-Rafizadeh C, Wang Y, Bernier M, Roth J. Glucagon-like peptide-1(7-36) amide (GLP-1) enhances insulinstimulated glucose metabolism in 3T3-L1 adipocytes: one of several potential extrapancreatic sites of GLP-1 action. Endocrinology. 1994; 135(5):2070-2075.

8. Dunphy JL, Taylor RG, Fuller PJ. Tissue distribution of rat glucagon receptor and GLP-1 receptor gene expression. Mol Cell Endocrinol. 1998;141(1-2):179-186.

9. Bucinskaite V, Tolessa T, Pedersen J, et al. Receptor-mediated activation of gastric vagal afferents by glucagon-like peptide-1 in the rat. Neurogastroenterol Motil. 2009;21(9):978-e78.

10. Doyle ME, Egan JM. Mechanisms of action of glucagon-like peptide 1 in the pancreas. Pharmacol Ther. 2007;113(3):546-593.

11. Nauck MA, Heimesaat MM, Orskov C, Holst JJ, Ebert R, Creutzfeldt W. Preserved incretin activity of glucagon-like peptide 1 [7-36 amide] but not of synthetic human gastric inhibitory polypeptide in patients with type-2 diabetes mellitus. J Clin Invest. 1993;91(1):301-307.

12. Nauck MA, Heimesaat MM, Behle K, et al. Effects of glucagon-like peptide 1 on counterregulatory hormone responses, cognitive functions, and insulin secretion during hyperinsulinemic, stepped hypoglycemic clamp experiments in healthy volunteers. J Clin Endocrinol Metab. 2002;87(3):1239-1246. 
13. Nauck MA, Kleine N, Orskov C, Holst JJ, Willms B, Creutzfeldt W. Normalization of fasting hyperglycaemia by exogenous glucagon-like peptide 1 (7-36 amide) in type 2 (non-insulin-dependent) diabetic patients. Diabetologia. 1993;36(8):741-744.

14. Meier JJ, Gallwitz B, Salmen S, et al. Normalization of glucose concentrations and deceleration of gastric emptying after solid meals during intravenous glucagon-like peptide 1 in patients with type 2 diabetes. $J$ Clin Endocrinol Metab. 2003;88(6):2719-2725.

15. Naslund E, Gutniak M, Skogar S, Rossner S, Hellstrom PM. Glucagon-like peptide 1 increases the period of postprandial satiety and slows gastric emptying in obese men. Am J Clin Nutr.1998;68(3): $525-530$.

16. Verdich C, Flint A, Gutzwiller JP, et al. A meta-analysis of the effect of glucagon-like peptide-1 (7-36) amide on ad libitum energy intake in humans. J Clin Endocrinol Metab. 2001;86(9):4382-4289.

17. Kieffer TJ, McIntosh CH, Pederson RA. Degradation of glucosedependent insulinotropic polypeptide and truncated glucagon-like peptide 1 in vitro and in vivo by dipeptidyl peptidase IV. Endocrinology. 1995;136(8):3585-3596.

18. Hansen L, Deacon CF, Orskov C, Holst JJ. Glucagon-like peptide-1(7-36)amide is transformed to glucagon-like peptide-1-(9-36)amide by dipeptidyl peptidase IV in the capillaries supplying the L cells of the porcine intestine. Endocrinology. 1999;140(11):5356-5363.

19. Knudsen LB, Nielsen PF, Huusfeldt PO, et al. Potent derivatives of glucagon-like peptide-1 with pharmacokinetic properties suitable for once daily administration. J Med Chem. 2000;43(9):1664-1669.

20. Chia CW, Egan JM. Incretin-based therapies in type 2 diabetes mellitus. $J$ Clin Endocrinol Metab. 2008;93(10):3703-3716.

21. Thorens B, Porret A, Buhler L, Deng SP, Morel P, Widmann C. Cloning and functional expression of the human islet GLP-1 receptor. Demonstration that exendin-4 is an agonist and exendin-(9-39) an antagonist of the receptor. Diabetes.1993;42(11):1678-1682.

22. Simonsen L, Holst JJ, Deacon CF. Exendin-4, but not glucagon-like peptide-1, is cleared exclusively by glomerular filtration in anaesthetised pigs. Diabetologia. 2006;49(4):706-712.

23. Linnebjerg H, Kothare PA, Park S, et al. Effect of renal impairment on the pharmacokinetics of exenatide. Br J Clin Pharmacol. 2007;64(3): 317-327.

24. Linnebjerg H, Kothare PA, Skrivanek Z, et al. Exenatide: effect of injection time on postprandial glucose in patients with Type 2 diabetes. Diabet Med. 2006;23(3):240-245.

25. Jacobsen LV, Hindsberger C, Robson R, Zdravkovic M. Effect of renal impairment on the pharmacokinetics of the GLP-1 analogue liraglutide. Br J Clin Pharmacol. 2009;68(6):898-905.

26. Egan JM, Meneilly GS, Elahi D. Effects of 1-mo bolus subcutaneous administration of exendin-4 in type 2 diabetes. Am J Physiol Endocrinol Metab. 2003;284(6):E1072-E1079.

27. Fineman MS, Bicsak TA, Shen LZ, et al. Effect on glycemic control of exenatide (synthetic exendin-4) additive to existing metformin and/or sulfonylurea treatment in patients with type 2 diabetes. Diabetes Care. 2003; 26(8):2370-2377.

28. Buse JB, Henry RR, Han J, Kim DD, Fineman MS, Baron AD. Effects of exenatide (exendin-4) on glycemic control over 30 weeks in sulfonylurea-treated patients with type 2 diabetes. Diabetes Care. 2004;27(11):2628-2635.

29. DeFronzo RA, Ratner RE, Han J, Kim DD, Fineman MS, Baron AD. Effects of exenatide (exendin-4) on glycemic control and weight over 30 weeks in metformin-treated patients with type 2 diabetes. Diabetes Care. 2005;28(5):1092-1100.

30. Kendall DM, Riddle MC, Rosenstock J, et al. Effects of exenatide (exendin-4) on glycemic control over 30 weeks in patients with type 2 diabetes treated with metformin and a sulfonylurea. Diabetes Care. 2005;28(5):1083-1091.

31. Zinman B, Hoogwerf BJ, Duran Garcia S, et al. The effect of adding exenatide to a thiazolidinedione in suboptimally controlled type 2 diabetes: a randomized trial. Ann Intern Med. 2007;146(7): 477-485.
32. DeFronzo RA, Triplitt C, Qu Y, Lewis MS, Maggs D, Glass LC. Effects of exenatide plus rosiglitazone on Bbta cell function and insulin sensitivity in subjects with type 2 diabetes on metformin. Diabetes Care. 2010;33(5):951-957.

33. Heine RJ, Van Gaal LF, Johns D, Mihm MJ, Widel MH, Brodows RG. Exenatide versus insulin glargine in patients with suboptimally controlled type 2 diabetes: a randomized trial. Ann Intern Med. 2005;143(8):559-569

34. Barnett AH, Burger J, Johns D, et al. Tolerability and efficacy of exenatide and titrated insulin glargine in adult patients with type 2 diabetes previously uncontrolled with metformin or a sulfonylurea: a multinational, randomized, open-label, two-period, crossover noninferiority trial. Clin Ther. 2007;29(11):2333-2348.

35. Nauck MA, Duran S, Kim D, et al. A comparison of twice-daily exenatide and biphasic insulin aspart in patients with type 2 diabetes who were suboptimally controlled with sulfonylurea and metformin: a non-inferiority study. Diabetologia. 2007;50(2):259-267.

36. Bunck MC, Diamant M, Corner A, et al. One-year treatment with exenatide improves beta-cell function, compared with insulin glargine, in metformin-treated type 2 diabetic patients: a randomized, controlled trial. Diabetes Care. 2009;32(5):762-768.

37. Klonoff DC, Buse JB, Nielsen LL, et al. Exenatide effects on diabetes, obesity, cardiovascular risk factors and hepatic biomarkers in patients with type 2 diabetes treated for at least 3 years. Curr Med Res Opin. 2008;24(1):275-286.

38. Davies MJ, Donnelly R, Barnett AH, Jones S, Nicolay C, Kilcoyne A. Exenatide compared with long-acting insulin to achieve glycaemic control with minimal weight gain in patients with type 2 diabetes: results of the Helping Evaluate Exenatide in patients with diabetes compared with Long-Acting insulin (HEELA) study. Diabetes Obes Metab. 2009;11(12):1153-1162.

39. Moretto TJ, Milton DR, Ridge TD, et al. Efficacy and tolerability of exenatide monotherapy over 24 weeks in antidiabetic drug-naive patients with type 2 diabetes: a randomized, double-blind, placebocontrolled, parallel-group study. Clin Ther. 2008;30(8):1448-1460.

40. McClenaghan NH, Flatt PR, Ball AJ. Actions of glucagon-like peptide-1 on KATP channel-dependent and -independent effects of glucose, sulphonylureas and nateglinide. J Endocrinol. 2006;190(3):889-896.

41. Fineman MS, Shen LZ, Taylor K, Kim DD, Baron AD. Effectiveness of progressive dose-escalation of exenatide (exendin-4) in reducing dose-limiting side effects in subjects with type 2 diabetes. Diabetes Metab Res Rev. 2004;20(5):411-417.

42. Sheffield CA, Kane MP, Busch RS, Bakst G, Abelseth JM, Hamilton RA. Safety and efficacy of exenatide in combination with insulin in patients with type 2 diabetes mellitus. Endocr Pract. 2008;14(3):285-292.

43. Yoon NM, Cavaghan MK, Brunelle RL, Roach P. Exenatide added to insulin therapy: a retrospective review of clinical practice over two years in an academic endocrinology outpatient setting. Clin Ther. 2009; 31(7):1511-1523.

44. Feinglos MN, Saad MF, Pi-Sunyer FX, An B, Santiago O. Effects of liraglutide (NN2211), a long-acting GLP-1 analogue, on glycaemic control and bodyweight in subjects with Type 2 diabetes. Diabet Med. 2005;22(8):1016-1023.

45. Madsbad S, Schmitz O, Ranstam J, Jakobsen G, Matthews DR. Improved glycemic control with no weight increase in patients with type 2 diabetes after once-daily treatment with the long-acting glucagonlike peptide 1 analog liraglutide (NN2211): a 12-week, double-blind, randomized, controlled trial. Diabetes Care. 2004;27(6):1335-1342.

46. Nauck MA, Hompesch M, Filipczak R, Le TD, Zdravkovic M, Gumprecht J. Five weeks of treatment with the GLP-1 analogue liraglutide improves glycaemic control and lowers body weight in subjects with type 2 diabetes. Exp Clin Endocrinol Diabetes. 2006;114(8):417-423.

47. Vilsboll T, Zdravkovic M, Le-Thi T, et al. Liraglutide, a longacting human glucagon-like peptide-1 analog, given as monotherapy significantly improves glycemic control and lowers body weight without risk of hypoglycemia in patients with type 2 diabetes. Diabetes Care. 2007;30(6):1608-1610. 
48. Garber A, Henry R, Ratner R, et al. Liraglutide versus glimepiride monotherapy for type 2 diabetes (LEAD-3 Mono): a randomised, 52-week, phase III, double-blind, parallel-treatment trial. Lancet. 2009; 373(9662):473-481.

49. Nauck M, Frid A, Hermansen K, et al. Efficacy and safety comparison of liraglutide, glimepiride, and placebo, all in combination with metformin, in type 2 diabetes: the LEAD (liraglutide effect and action in diabetes)-2 study. Diabetes Care. 2009;32(1):84-90.

50. Marre M, Shaw J, Brandle M, et al. Liraglutide, a once-daily human GLP-1 analogue, added to a sulphonylurea over 26 weeks produces greater improvements in glycaemic and weight control compared with adding rosiglitazone or placebo in subjects with Type 2 diabetes (LEAD-1 SU). Diabet Med. 2009;26(3):268-278.

51. Buse JB, Rosenstock J, Sesti G, et al. Liraglutide once a day versus exenatide twice a day for type 2 diabetes: a 26-week randomised, parallel-group, multinational, open-label trial (LEAD-6). Lancet. 2009; 374(9683):39-47.

52. Zinman B, Gerich J, Buse JB, et al. Efficacy and safety of the human glucagon-like peptide-1 analog liraglutide in combination with metformin and thiazolidinedione in patients with type 2 diabetes (LEAD-4 Met+TZD). Diabetes Care. 2009;32(7):1224-1230.

53. Russell-Jones D, Vaag A, Schmitz O, et al. Liraglutide vs insulin glargine and placebo in combination with metformin and sulfonylurea therapy in type 2 diabetes mellitus (LEAD-5 met+SU): a randomised controlled trial. Diabetologia. 2009;52(10):2046-2055.

54. Parks M, Rosebraugh $\mathrm{C}$. Weighing risks and benefits of liraglutide the FDA's review of a new antidiabetic therapy. $N$ Engl J Med. 2010; 362(9):774-777.

55. Bjerre Knudsen L, Madsen LW, Andersen S, et al. Glucagon-like Peptide-1 receptor agonists activate rodent thyroid C-cells causing calcitonin release and C-cell proliferation. Endocrinology. 2010;151(4): 1473-1486.

56. Ratner RE, Maggs D, Nielsen LL, et al. Long-term effects of exenatide therapy over 82 weeks on glycaemic control and weight in over-weight metformin-treated patients with type 2 diabetes mellitus. Diabetes Obes Metab. 2006;8(4):419-428.

57. Elkind-Hirsch K, Marrioneaux O, Bhushan M, Vernor D, Bhushan R. Comparison of single and combined treatment with exenatide and metformin on menstrual cyclicity in overweight women with polycystic ovary syndrome. J Clin Endocrinol Metab. 2008;93(7):2670-2678.
58. Jendle J, Nauck MA, Matthews DR, et al. Weight loss with liraglutide, a once-daily human glucagon-like peptide-1 analogue for type 2 diabetes treatment as monotherapy or added to metformin, is primarily as a result of a reduction in fat tissue. Diabetes Obes Metab. 2009;11(12): 1163-1172.

59. Astrup A, Rossner S, Van Gaal L, et al. Effects of liraglutide in the treatment of obesity: a randomised, double-blind, placebo-controlled study. Lancet. 2009;374(9701):1606-1616.

60. Garber A, Marre M, Blonde L, et al. Influence of initial hyperglycaemia, weight and age on the blood glucose lowering efficacy and incidence of hypoglycaemic symptoms with a single-tablet metformin-glibenclamide therapy (Glucovance) in type 2 diabetes. Diabetes Obes Metab. 2003;5(3):171-179.

61. Gutzwiller JP, Tschopp S, Bock A, et al. Glucagon-like peptide 1 induces natriuresis in healthy subjects and in insulin-resistant obese men. J Clin Endocrinol Metab. 2004;89(6):3055-3061.

62. Gill A, Hoogwerf BJ, Burger J, et al. Effect of exenatide on heart rate and blood pressure in subjects with type 2 diabetes mellitus: a doubleblind, placebo-controlled, randomized pilot study. Cardiovasc Diabetol. 2010;9:6.

63. Okerson T, Yan P, Stonehouse A, Brodows R. Effects of exenatide on systolic blood pressure in subjects with type 2 diabetes. Am J Hypertens. 2010;23(3):334-339.

64. Golpon HA, Puechner A, Welte T, Wichert PV, Feddersen CO. Vasorelaxant effect of glucagon-like peptide-(7-36)amide and amylin on the pulmonary circulation of the rat. Regul Pept. 2001;102(2-3): 81-86.

65. Green BD, Hand KV, Dougan JE, McDonnell BM, Cassidy RS, Grieve DJ. GLP-1 and related peptides cause concentration-dependent relaxation of rat aorta through a pathway involving KATP and cAMP. Arch Biochem Biophys. 2008;478(2):136-142.

66. Nystrom T, Gonon AT, Sjoholm A, Pernow J. Glucagon-like peptide-1 relaxes rat conduit arteries via an endothelium-independent mechanism. Regul Pept. 2005;125(1-3):173-177.

67. Nystrom T, Gutniak MK, Zhang Q, et al. Effects of glucagon-like peptide- 1 on endothelial function in type 2 diabetes patients with stable coronary artery disease. Am J Physiol Endocrinol Metab. 2004; 287(6):E1209-E1215.

68. Drucker DJ, Buse JB, Taylor K, et al. Exenatide once weekly versus twice daily for the treatment of type 2 diabetes: a randomised, openlabel, non-inferiority study. Lancet. 2008;372(9645):1240-1250.
Therapeutics and Clinical Risk Management

\section{Publish your work in this journal}

Therapeutics and Clinical Risk Management is an international, peerreviewed journal of clinical therapeutics and risk management, focusing on concise rapid reporting of clinical studies in all therapeutic areas, outcomes, safety, and programs for the effective, safe, and sustained use of medicines. This journal is indexed on PubMed Central, CAS,

\section{Dovepress}

EMBase, Scopus and the Elsevier Bibliographic databases. The manuscript management system is completely online and includes a very quick and fair peer-review system, which is all easy to use. Visit http://www.dovepress.com/testimonials.php to read real quotes from published authors. 